\title{
Article \\ On the Origin of Reduced Cytotoxicity of Germanium-Doped Diamond-Like Carbon: Role of Top Surface Composition and Bonding
}

\author{
Josef Zemek $^{1, *}$, Petr Jiricek ${ }^{1}$, Jana Houdkova ${ }^{1}$, Martin Ledinsky ${ }^{1}$, Miroslav Jelinek ${ }^{1,2}$ and Tomas Kocourek ${ }^{1,2} \mathbb{D}$ \\ 1 Institute of Physics of the Czech Academy of Sciences, Na Slovance 2, 18221 Prague 8, Czech Republic; \\ jiricek@fzu.cz (P.J.); houdkova@fzu.cz (J.H.); ledinsky@fzu.cz (M.L.); jelinek@fzu.cz (M.J.); \\ kocourek@fzu.cz (T.K.) \\ 2 Faculty of Biomedical Engineering, Czech Technical University in Prague, nam. Sitna 3105, \\ 27201 Kladno, Czech Republic \\ * Correspondence: zemek@fzu.cz
}

\section{check for} updates

Citation: Zemek, J.; Jiricek, P.; Houdkova, J.; Ledinsky, M.; Jelinek, M.; Kocourek, T. On the Origin of Reduced Cytotoxicity of Germanium-Doped Diamond-Like Carbon: Role of Top Surface Composition and Bonding. Nanomaterials 2021, 11, 567. https: / / doi.org/10.3390/ nano11030567

Academic Editor: Alessio Mezzi

Received: 11 February 2021

Accepted: 19 February 2021

Published: 25 February 2021

Publisher's Note: MDPI stays neutral with regard to jurisdictional claims in published maps and institutional affiliations.

Copyright: (c) 2021 by the authors. Licensee MDPI, Basel, Switzerland. This article is an open access article distributed under the terms and conditions of the Creative Commons Attribution (CC BY) license (https:/ / creativecommons.org/licenses/by/ $4.0 /)$.

\begin{abstract}
This work attempts to understand the behaviour of Ge-induced cytotoxicity of germaniumdoped hydrogen-free diamond-like carbon (DLC) films recently thoroughly studied and published by Jelinek et al. At a low doping level, the films showed no cytotoxicity, while at a higher doping level, the films were found to exhibit medium to high cytotoxicity. We demonstrate, using surface-sensitive methods-two-angle X-ray-induced core-level photoelectron spectroscopy (ARXPS) and Low Energy Ion Scattering (LEIS) spectroscopy, that at a low doping level, the layers are capped by a carbon film which impedes the contact of Ge species with tissue. For higher Ge content in the DLC films, oxidized Ge species are located at the top surface of the layers, provoking cytotoxicity. The present results indicate no threshold for Ge concentration in cell culture substrate to avoid a severe toxic reaction.
\end{abstract}

Keywords: germanium; diamond-like carbon; photoelectron spectroscopy; low energy ion scattering spectroscopy; Raman spectroscopy; carbon capping film; cytotoxicity

\section{Introduction}

Diamond-like carbon (DLC) is a metastable form of amorphous carbon with plentiful interesting mechanical, optical and electronic properties, mainly influenced by the $\mathrm{sp}^{3} / \mathrm{sp}^{2}$ ratio and by the occurrence of hydrogen or other elements. The balance of the components and the incorporation of additional elements can — to certain extent - be tuned to tailor the coatings for a particular application [1-4]. In biological and medical applications, DLC coatings are often used as barrier layers to prevent corrosion phenomena manifesting themselves by releasing toxic ions from the surfaces of metallic implants into the surrounding tissue $[5,6]$. The coatings are considered as biocompatible with none or low cytotoxicity. For nanostructured carbon materials, such as graphene, fullerene and nanotubes, the picture is more complicated [7,8]. A weak property of the undoped DLC layers with a high $\mathrm{sp}^{3}$ component is a relatively high internal stress resulting in a poor adhesion. This deficiency can be overcome by doping suitable element(s) during a DLC layer deposition. Introducing elements, such as B, N, Ca, P, Ge, Ti, Si leads to improved adhesion mainly due to doping-induced bonding transformation from $\mathrm{C} \mathrm{sp}{ }^{3}$ hybridization prominent in undoped DLC to $\mathrm{C} \mathrm{sp}^{2}$ in doped DLC [9]. The next requirement on the doped DLC layers is no or weak cytotoxicity, which should be carefully tested for each dopant element and dopant concentration used.

Germanium is considered to be a nonessential element with low acute toxicity. Ge exerts prophylactic and therapeutic effects in the treatments of cancer and Human immunodeficiency Virus (HIV) infections [10-12], immune activation effects for bio-germanium [13], and antioxidant effects [14]. Ge-containing dietary supplements were widely used in the 1970 s in Japan and later in other countries to promote health and cure diseases. However, a 
prolonged intake of Ge-containing products was associated with renal failure with characteristic renal dysfunction and tubular degeneration, anemia, myopathy, neuropathy, tissue Ge accumulation, and even death [15]. Inorganic $\left(\mathrm{GeO}_{2}\right)$ and organic $(\mathrm{Ge}-132)$ germanium was found to be toxic to lettuce growth [16]. Cytotoxicity of surface-functionalized silicon and germanium nanoparticles was observed [17]. Germanium nanocrystals doped with boron and phosphorous showed significant toxicity to a Gram-negative bacterium Shewanella oneidensis, while the undoped nanocrystals were found to be nontoxic [18]. Antimicrobial properties of a modified multilayer (undoped DLC and Ge-doped DLC coatings with Ge-doped top layer) have been investigated by Robertson et al. [19]. Ge-doped DLC coatings showed a significant anti-biofouling effect on a Gram-negative bacterium Pseudomonas aeruginosa. The authors did not attribute this effect to Ge doping alone because P. aeruginosa biomass reduction was also observed for the undoped DLC layers [19]. Recently, no cytotoxicity has been followed for a low doping level of Ge-doped DLC layers by Jelinek et al., while for higher doping level the cytotoxicity has been demonstrated, associated with the production of reactive oxygen species. The authors concluded that there is a threshold in Ge cytotoxicity in Ge-doped DLC layers [20].

From the above literature one can infer that Ge can promote health and can be detrimental to health, depending on conditions. Until now, a few reports on Ge-doped DLC layers have appeared. Existing studies mostly provide bulk-like information about Gedoped carbon layers $[19,20]$. However, surface properties, e.g., surface composition and surface chemistry, are of critical importance for biocompatibility $[5,6]$.

The goal of the present work is to understand the behaviour of Ge-doped DLC layers in relation to the cytotoxicity thoroughly examined in [20]. Especially, we try to reveal the origin of the threshold in Ge-doped DLC layers. Considering that the interaction between a solid surface and tissue is governed by the composition and the chemical bonding of elements located at the top surface and just beneath the surface of the sample, we determined the composition and chemical bonding of atoms located at the surface of the analysed layers by applying two-angle X-ray induced core-level photoelectron spectroscopy (ARXPS) and Low Energy Ion Scattering (LEIS). Raman spectroscopy (RS) was used to validate the bonding transformation from $\mathrm{C} \mathrm{sp}$ to $\mathrm{C} \mathrm{sp} \mathrm{p}^{2}$ induced by Ge doping deduced from the $C$ 1s spectra.

\section{Materials and Methods}

\subsection{Deposition}

DLC:Ge layers, deposited by the dual pulse laser deposition (PLD) using two KrF excimer lasers, were prepared concurrently with the samples tested for cytotoxicity [20] on substrates from fused silica. More details about the layer deposition can be found elsewhere [20]. In brief, the first laser was focused onto a high purity graphite target, while the second beam was focused on a Ge target. The film thickness reached about $160 \mathrm{~nm}$. An undoped DLC layer was deposited and analysed to reveal the effect of Ge doping in DLC:Ge layers.

\subsection{Spectrometers}

Photoelectron spectra were recorded with an AXIS-Supra photoelectron spectrometer (Kratos Analytical Ltd., Manchester, UK), using monochromatized $\mathrm{Al} \mathrm{K} \alpha$ radiation $\left(1486.6 \mathrm{eV}, 300 \mathrm{~W}\right.$, area analysed $\left.-0.7 \times 0.3 \mathrm{~mm}^{2}\right)$. The samples were analysed ex-situ. Only the peaks of $\mathrm{C}, \mathrm{Ge}$, and $\mathrm{O}$ were observed in X-ray photoelectron spectroscopy (XPS) survey spectra, see Figure 1. 


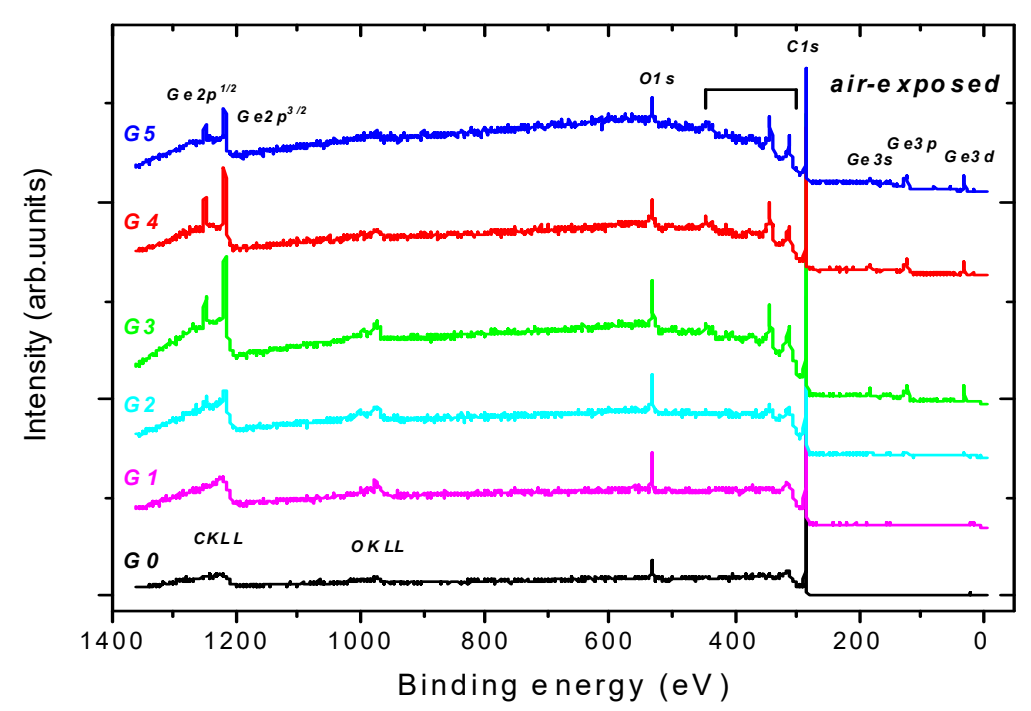

Figure 1. Typical photoelectron survey spectra recorded at normal electron emission angle from the surface of the undoped diamond-like carbon G0 and Ge-doped samples G1-G5. The samples labelling is introduced in Table 1.

Table 1. Apparent XPS composition data recorded from the undoped DLC and Ge-doped DLC layers. The surface-related contents of the Ge derived from the XPS spectra is compared with the bulk-like values derived from the WDS spectra [20]. The $C \mathrm{sp}^{2}$ and $C \mathrm{sp}^{3}$ fractions originate from a peak-fitting of the $\mathrm{C} 1 \mathrm{~s}$ line, which will be introduced below.

\begin{tabular}{ccccccccc}
\hline Sample & $\begin{array}{c}\text { Ge } \\
\text { WDS } \\
\text { (at. \%) }\end{array}$ & $\begin{array}{c}\text { Ge } \\
\text { (at. \%) }\end{array}$ & $\begin{array}{c}\text { XPS } \\
\text { (at. \%) }\end{array}$ & $\begin{array}{c}\text { CPS } \\
\text { (at. \%) }\end{array}$ & $\begin{array}{c}\text { C sp } \\
\text { (at. \%) }\end{array}$ & $\begin{array}{c}\mathbf{C ~ s p}^{\mathbf{3}} \\
\text { (at. \%) }\end{array}$ & $\begin{array}{c}\text { C sp }^{\mathbf{3} /} \\
\text { C sp }^{\mathbf{2}}\end{array}$ \\
\hline G0 & Undoped DLC & - & 0.0 & 5.1 & 94.9 & 29.9 & 61.4 & 2.05 \\
G1 & DLC:Ge & 1 & 0.2 & 3.8 & 96.0 & 50.1 & 41.8 & 0.83 \\
G2 & DLC:Ge & 2.5 & 0.8 & 4.6 & 94.6 & 50.5 & 39.1 & 0.78 \\
G3 & DLC:Ge & 5 & 2.2 & 6.8 & 91.0 & 42.8 & 40.2 & 0.94 \\
G4 & DLC:Ge & 9 & 4.1 & 6.1 & 89.8 & 50.3 & 29.9 & 0.59 \\
G5 & DLC:Ge & 12 & 6.0 & 7.3 & 86.7 & 52.5 & 26.3 & 0.50 \\
\hline
\end{tabular}

The high-energy resolved spectra of $\mathrm{C} 1 \mathrm{~s}, \mathrm{Ge} 3 \mathrm{~d}$ and $\mathrm{O} 1 \mathrm{~s}$ were collected with a pass energy of $10 \mathrm{eV}$ and with a step of $0.05 \mathrm{eV}$, resulting in an overall energy resolution of $0.45 \mathrm{eV}$, measured on the width of the $\mathrm{Ag} 3 \mathrm{~d}_{5 / 2}$ line. Binding energy referencing was performed with respect to the $\mathrm{C} \mathrm{sp}{ }^{2}$ contribution, which peaked at $284.3 \mathrm{eV}$. Quantification was performed using the integrated peak areas of the $C 1 \mathrm{~s}, \mathrm{Ge} 3 \mathrm{~d}$ and $\mathrm{O} 1 \mathrm{~s}$ core level spectra after subtracting the standard Shirley's electron inelastic background and the atomic sensitivity factors given in ESCApe software, version 1.4 (Kratos Analytical Ltd., Manchester, UK). The $\mathrm{C}$ 1s spectra were analysed by peak fitting using the asymmetric pseudo-Voigt peak shape to separate the $\mathrm{C} \mathrm{sp}^{2}$ bonds [21] and using the symmetric Voigt curves to separate the $C \mathrm{sp}^{3}$ contribution and other resolved bonding states in the $\mathrm{C} 1 \mathrm{~s}$ and Ge 3d spectral envelopes. LEIS measurements were performed with an AXIS-Supra photoelectron spectrometer (Kratos AnalyticalLtd., Manchester, UK) using ${ }^{4} \mathrm{He}$ as incident ions at a scattering angle of $130^{\circ}$ and ion energy of $1000 \mathrm{eV}$. Raman spectra were measured by using Renishaw inVia Reflex microspectrometer, (Renishaw, Wotton-under-Edge, UK) with an excitation wavelength of $442 \mathrm{~nm}$. The total laser power on the sample was decreased to $3 \mathrm{~mW}$ so as not to damage the film. The accumulation time was set to $100 \mathrm{~s}$ to increase the signal-to-noise ratio. 


\subsection{Concise Characterization of DLC: Ge Samples}

In the recent study of Ge-doped nanocomposite materials dedicated the cytotoxicity [20], the sample properties as surface roughness, morphology, bulk composition and optical transmittance were also examined. Here, we present only brief results important for closer connection the recent and the present studies. Surface roughness ranged from about $3 \mathrm{~nm}$ to $120 \mathrm{~nm}$, dependent on Ge concentration, due to small grain droplets located at the surfaces of the Ge-doped samples, as shown by scanning electron microscopy. The Ge dopant concentration averaged within whole layer thickness, measured by a wavelength dispersive $\mathrm{X}$-ray spectroscopy (WDS, JEOL Inc., Peabody, MA, USA), ranged from 0 at. $\%$ to 12 at. \% (see Table 1 ). The film transmittance in the UV-VIS and near-infrared regions generally decreased with increasing Ge content. Furthermore, the in vitro adhesion, proliferation, and toxicity of one of very sensitive cell lines (hepatic, Huh7) upon curing on Ge-doped DLC layers using various bioassays were investigated. A threshold for Ge concentration in the layers was identified. Ge concentration higher than 2.5 at. \% induced signs of cell death in hepatitis cells. Reactive oxygen species (ROS) production have been identified as a major reason for the cytotoxicity of examined layers.

\section{Results and Discussion}

\subsection{Common XPS Surface Characterization}

Apparent composition data derived from the $\mathrm{C} 1 \mathrm{~s}, \mathrm{O} 1 \mathrm{~s}$, and Ge $3 \mathrm{~d}$ spectra recorded at the normal photoelectron emission angle from the air-exposed surfaces of the samples, summarized in Table 1, are compared to the bulk-like Ge concentration values averaged within the whole layer derived from a wavelength dispersive $\mathrm{X}$-ray spectroscopy spectra (WDS) [20]. In addition, the content of $\mathrm{C} \mathrm{sp}^{2}, \mathrm{C} \mathrm{sp}^{3}$ contributions and their ratios is also included.

Typical high-energy resolved C 1 s and Ge $3 \mathrm{~d}$ spectra recorded at the normal emission angle from the undoped DLC and the Ge-doped DLC layers are shown in Figure 2. A peak-fit of the $\mathrm{C} 1 \mathrm{~s}$ and Ge $3 \mathrm{~d}$ spectra recorded from the undoped DLC and Ge-doped DLC layers is illustrated. The $C$ 1s envelopes indicate the following bonding states: The spectral intensity at $283.3 \mathrm{eV}$, ascribed to $\mathrm{C}-\mathrm{Ge}$ [22-26]; at $284.3 \mathrm{eV}$, ascribed to $\mathrm{C} \mathrm{sp}$; at $285.2 \mathrm{eV}$, ascribed to $\mathrm{C} \mathrm{sp}^{3}$ [23,27-30]; at $286.5 \mathrm{eV}$, ascribed to $\mathrm{C}-\mathrm{O}$; at $287.9 \mathrm{eV}$, ascribed to $\mathrm{C}=\mathrm{O}[21,31]$; at $288.7 \mathrm{eV}$, ascribed to the $\pi-\pi^{*}$ shake up satellite [30]. The Ge $3 \mathrm{~d}$ envelope indicates the following bonding states: The spectral intensity at $29.3 \mathrm{eV}$, ascribed to Ge-Ge [25,26]; at $30.2 \mathrm{eV}$, ascribed to $\mathrm{Ge}-\mathrm{C}[22,25]$; at $31.2 \mathrm{eV}$, ascribed to $\mathrm{GeO}[32,33]$; at $32.7 \mathrm{eV}$, ascribed to $\mathrm{GeO}_{2}[32,33]$.

From Table 1 and Figure 2 we deduce that:

(i) In-depth distribution of Ge atoms is non-homogeneous, because the Ge concentrations (WDS) averaged within the layer thickness are larger by a factor of two or even more than the XPS data. As a consequence, a near-surface region of the DLC:Ge samples is partially or fully depleted by Ge.

(ii) The $\mathrm{C} \mathrm{sp} / \mathrm{C} \mathrm{sp}$ ratio is highly influenced by Ge doping, indicating the dopinginduced structural evolution of carbon atoms hybridizations from $\mathrm{sp}^{3}$ to $\mathrm{sp}^{2}[9,34]$. This is clearly seen in Figure 2a where the dominating $C$ sp$^{3}$ contribution in $C$ 1s envelope for the undoped DLC layer G0 transforms step-by-step to the $\mathrm{C} \mathrm{sp}^{2}$ one with increasing Ge content in the Ge-doped DLC layers G1-G5.

(iii) $\mathrm{Ge}-\mathrm{C}$ bonds dominates in $\mathrm{Ge} 3 \mathrm{~d}$ envelope over the $\mathrm{Ge}-\mathrm{Ge}$ and $\mathrm{Ge}-\mathrm{O}$ bonding states. 


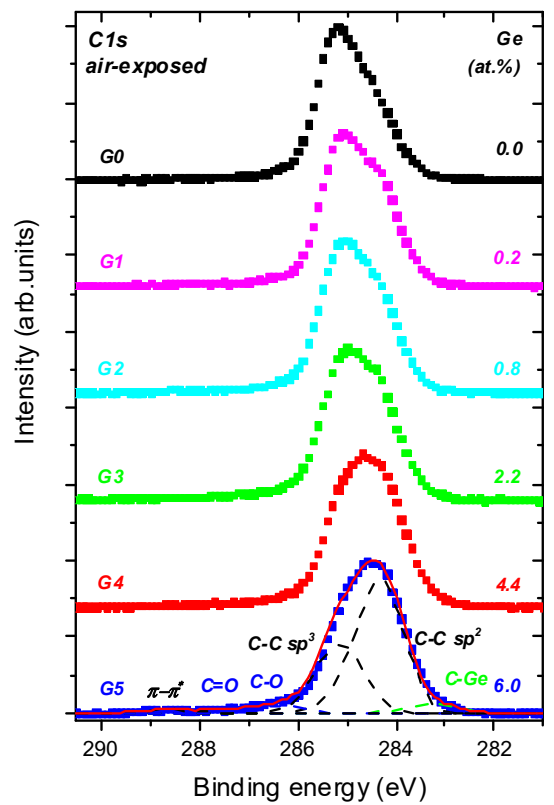

(a)

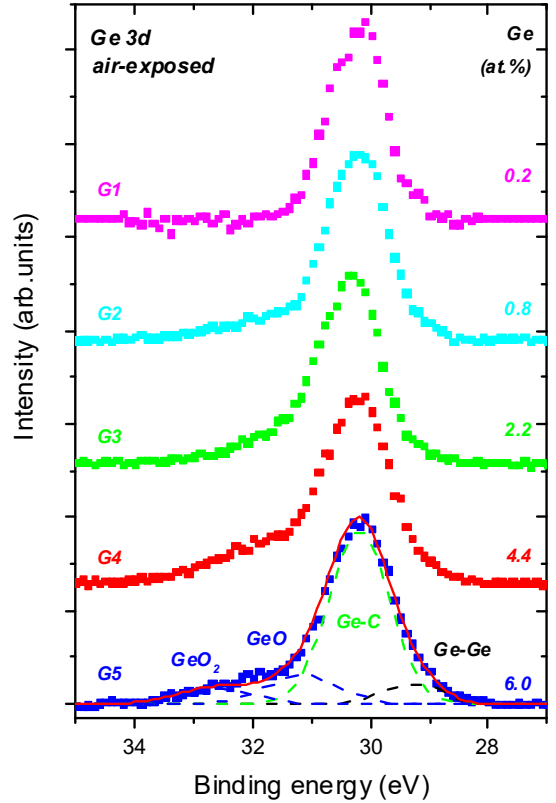

(b)

Figure 2. Exemplary high-energy resolved C 1s (a) and Ge 3d (b) spectra recorded from undoped and Ge-doped DLC layers at the normal emission angle, normalized to unity. Peak-fits of the resolved bonding states are illustrated.

\subsection{Surface Analysis by Using the Methods with Different Information Depths}

As mentioned in the Introduction, the interaction between the solid surface and its surroundings depends on the composition and chemical bonding at the top surface of the solid and by the composition and chemical bonding in a shallow sub-surface region $[5,6]$. However, it is not an easy task to analyse the top surface of the samples. Widely used surface-sensitive methods, such as XPS and Auger electron spectroscopy (AES), provide information averaged within their information depths (ID). ID represents the thickness of a surface layer from which $95 \%$ of the spectral intensity can be recorded. ID can be approximated by ID $=3 \lambda(E) \cos \alpha$, where $\lambda(E)$ is the inelastic mean free path (IMFP) of electrons in question, which depends on the electron energy $E$ and the material under analysis, and $\alpha$ is the electron emission angle measured from the surface normal. For example, ID $=6.3 \mathrm{~nm}$ is calculated for $\mathrm{C}$ 1s photoelectrons travelling in graphite excited by $\mathrm{Al} \mathrm{K} \alpha$ radiation recorded at the normal electron emission angle, while for an inclined emission angle of $70^{\circ}$ it is ID $=2.2 \mathrm{~nm}[35,36]$. Therefore, ID (and surface sensitivity) changes extensively with the electron emission angle. This effect can be used to obtain qualitative information about the surface and near-surface composition and chemistry $[9,27,37]$. Similar qualitative information can also be obtained by comparing electron spectra from the same element with the rather different kinetic energy of signal electrons [38]. A more direct and even a more surface-sensitive method is LEIS, known for its extreme surface sensitivity. It provides the composition of 1-2 surface atomic layers [39]. Here we present and compare the XPS spectra recorded at the normal electron emission angle, ID $6 \mathrm{~nm}$; the spectra recorded at an inclined electron emission angle of $70^{\circ}$, ID 2 nm; the LEIS spectra with ID $<1 \mathrm{~nm}$, and finally the RS spectra with ID 100 $\mathrm{nm}$.

Germanium content in a near-surface region of the analysed samples, derived from XPS spectra, is shown in Figure 3a for two different ID values. At the more surface sensitive geometry, $\alpha=70^{\circ}$, ID 2 $\mathrm{nm}$, Ge content increased with the sample number and therefore with the bulk-like Ge content summarized in Table 1, and then saturated, while for the $\alpha=0^{\circ}$, ID $6 \mathrm{~nm}$, the Ge percentage is increasing. 


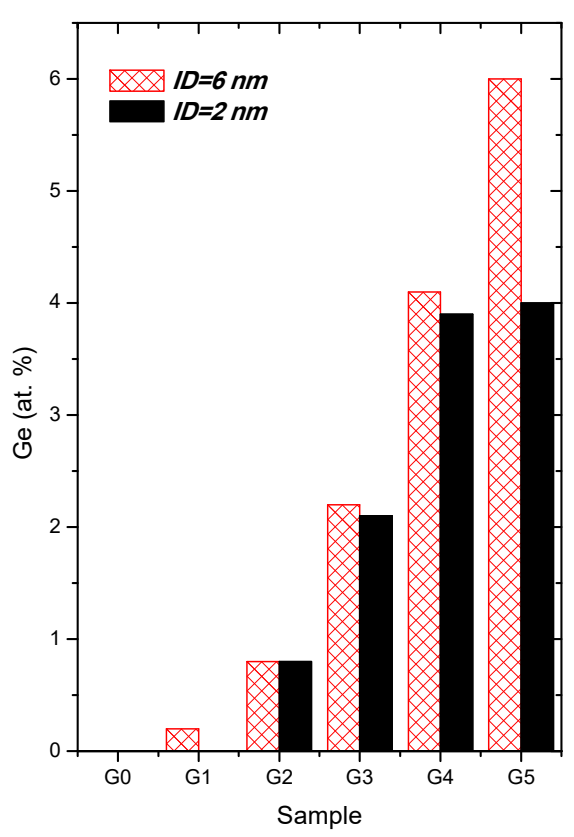

(a)

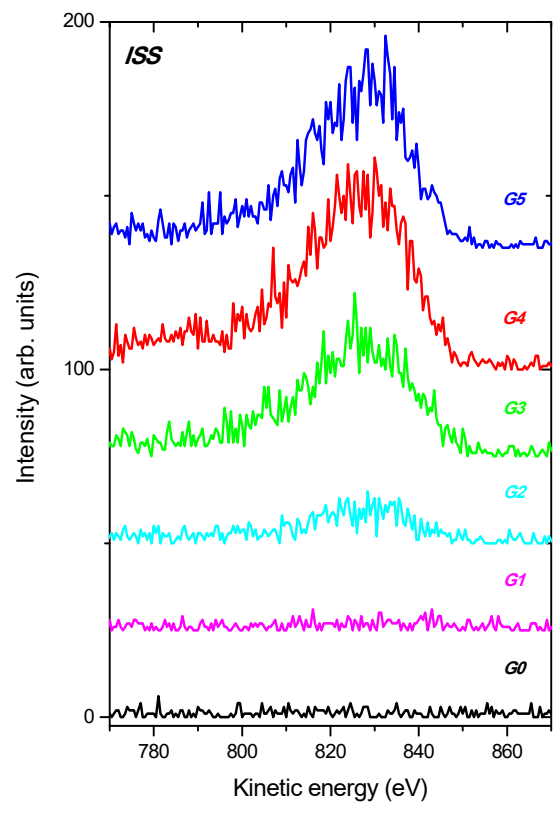

(b)

Figure 3. Percentage of Ge species in a surface region of the samples derived from XPS spectra evaluated from ID $=6 \mathrm{~nm}$ and $2 \mathrm{~nm}$ (a). Low energy ion scattering spectra (ID < $1 \mathrm{~nm}$ ) recorded from undoped DLC G0 and Ge-doped DLC G1-G5 samples, ascribed to $4 \mathrm{He}$ ion beam scattering at Ge atoms (b).

Note that no Ge content is found for the G1sample using the more surface-sensitive mode when ID $=2 \mathrm{~nm}$. This means the formation of a carbon capping film covering the surface of the sample. Ge concentration values calculated for both ID values are substantially lesser than the WDS data. This indicates that a near-surface region of the DLC:Ge layers is Ge-depleted, in agreement with the data in Table 1.

The sensitivity of LEIS for a light element as carbon is relatively poor since the ion scattering cross-sections scale with the atomic number. Moreover, a strong matrix effect occurs in low-energy $\mathrm{He}^{+}$ion scattering from carbon, which causes He ion neutralization $[40,41]$. As a consequence, the spectral signal of $\mathrm{He}^{+}$ions scattered at carbon atoms is very weak. However, the spectral signal induced by ${ }^{4} \mathrm{He}$ ions scattered from Ge atoms can be easily recorded, see Figure $3 \mathrm{~b}$. A peak at about $830 \mathrm{eV}$ is ascribed to ion scattering at Ge atoms [39,42]. Indeed, the spectral signal intensity from Ge atoms increased with the Ge content in a surface region of the analysed samples. Their peak areas 312, 941, 1226, and 1293 (in arbitrary units) for the G2-G5 samples, respectively, compare well with the Ge content derived from XPS spectra shown in Figure 3a and in Table 1. We underline that no spectral signal from Ge atoms is detected for the G0 sample (as expected) and for Ge-doped G1 sample. This verifies the formation of the carbon capping film at the surface of the G1 sample, as we already deduced from Figure 3a. The capping carbon film thickness $t$ can be estimated in the range of $2 \mathrm{~nm} \leq t<6 \mathrm{~nm}$.

As shown in Figure $2 b$, chemical bonds of germanium atoms and their in-depth location can be deduced from the Ge $3 \mathrm{~d}$ photoelectron spectra. The Ge $3 \mathrm{~d}$ spectra recorded from Ge-doped DLC G5 sample at two different emission angles and therefore at different surface sensitivities and their difference are displayed in Figure 4a. The difference shows marked changes in a region where the spectral signal from $\mathrm{Ge}-\mathrm{O}$ bonds is expected $[32,33]$. This indicates that the oxidized Ge species are present at the surface, because the intensity from $\mathrm{Ge}-\mathrm{O}$ bonds is enhanced in the $\mathrm{Ge} 3 \mathrm{~d}$ spectrum recorded within the more surface sensitive mode. Contrary, Ge bonded to $\mathrm{C}$ and Ge bonded to Ge are expected to be distributed beneath the surface of the samples [25]. Therefore, the Ge oxide species can easily 
interact with a tissue to provoke cytotoxicity. Indeed, the Ge oxides, particularly the $\mathrm{GeO}_{2}$ can be responsible for the toxic behaviour, as exemplified in previous studies $[16,19,43,44]$.

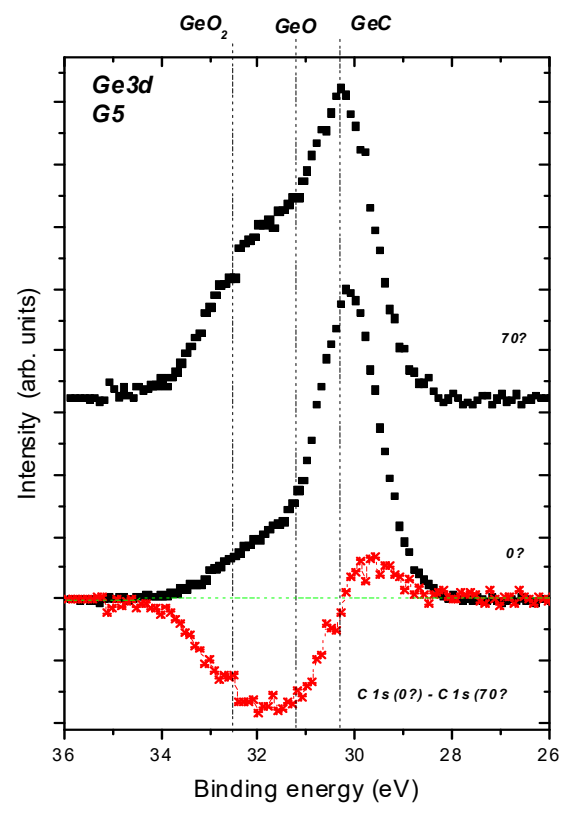

(a)

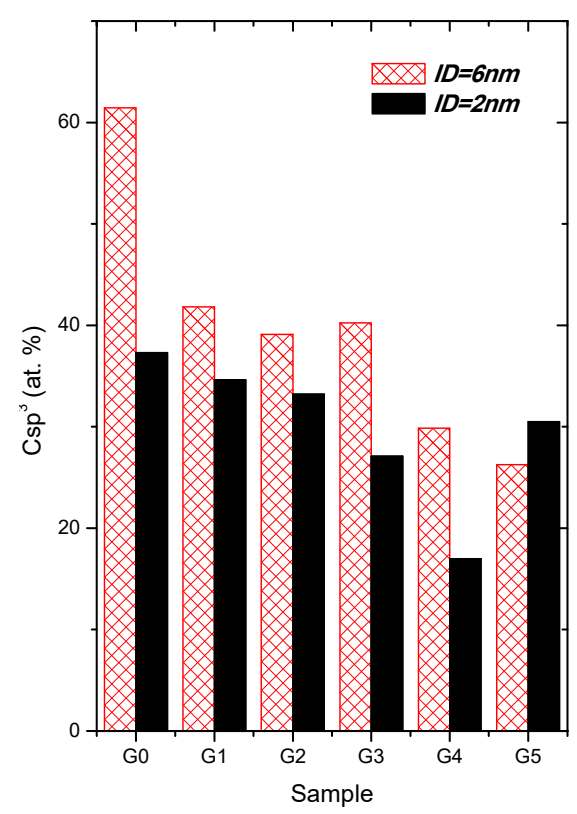

(b)

Figure 4. Typical Ge 3d spectra recorded from the DLC:Ge sample G5 at the normal emission angle (ID 6 nm), at the inclined emission angle (ID 2 $\mathrm{nm}$ ) and their difference (a). Content of $\mathrm{C} \mathrm{sp}{ }^{3}$ contributions for all analysed samples fitted from the $\mathrm{C}$ 1 s spectral envelopes recorded at the normal and the inclined emission angles and therefore at two different IDs (b).

Figure $4 \mathrm{~b}$ illustrates the next important feature induced by Ge doping-the structural evolution from dominating $C \mathrm{sp}^{3}$ component to $C \mathrm{sp}^{2}$ component induced by Ge doping examined for both ID values, $6 \mathrm{~nm}$ and $2 \mathrm{~nm}$. The $C \mathrm{sp}^{3} / \mathrm{Csp}^{2}$ ratio plays an important role also in the biological activity of carbon materials [8]. The $\mathrm{C} \mathrm{sp} \mathrm{s}^{3}$ content decreases and therefore the $\mathrm{C} \mathrm{sp}{ }^{2}$ content rises with an increasing Ge doping level at the surfaces of the samples, but the G5 sample for ID $=2 \mathrm{~nm}$. The drop is more pronounced for the less surface sensitive geometry, ID $=6 \mathrm{~nm}$, i.e., for a sub-surface region of the samples, because the top surface of the undoped sample is $C \mathrm{sp}^{2}$ rich and the $\mathrm{C} \mathrm{sp}$ hybridization dominates beneath the surface. The surface enrichment by the $C \mathrm{sp}^{2}$ component was observed for the undoped DLC layers prepared by PLD [9] and by other deposition methods [45,46]. Moreover, the surface enrichment by $\mathrm{C} \mathrm{sp}^{2}$ is consistent with the results of simulated amorphous layer growth $[47,48]$. Regarding the G5 sample, where the $\mathrm{C} \mathrm{sp}{ }^{3}$ contribution rose in a shallow surface film of $2 \mathrm{~nm}$, this behaviour can be a sign of a dual structural transformation observed recently for Ca-doped DLC layers. The top surface of the Cadoped layers is dominantly formed by the $\mathrm{C} \mathrm{sp}{ }^{3}$ hybridization, while beneath the surface the $\mathrm{C} \mathrm{sp}{ }^{2}$ contribution is prevailing [9].

Two Raman bands are usually characteristic of DLC materials, the D-band and the G-band. For the undoped DLC layer G0 the G band is centred at $1580 \mathrm{~cm}^{-1}$, while no $\mathrm{D}$ band at $\sim 1340 \mathrm{~cm}^{-1}$ is detected. This spectral shape is typical of high-quality DLC films [49] and is almost preserved also for the Ge-doped layers (see Figure 5). The G band is shifted to lower energies $\sim 1510 \mathrm{~cm}^{-1}$ and, at the same time, getting wider with Ge content. The intensity of the G band significantly decreases with Ge content as well. These are the main signs of an increasing sp ${ }^{2}$ content with Ge doping [22,49], in accord with the above angular-resolved X-ray induced photoelectron spectroscopy (ARXPS) data. 


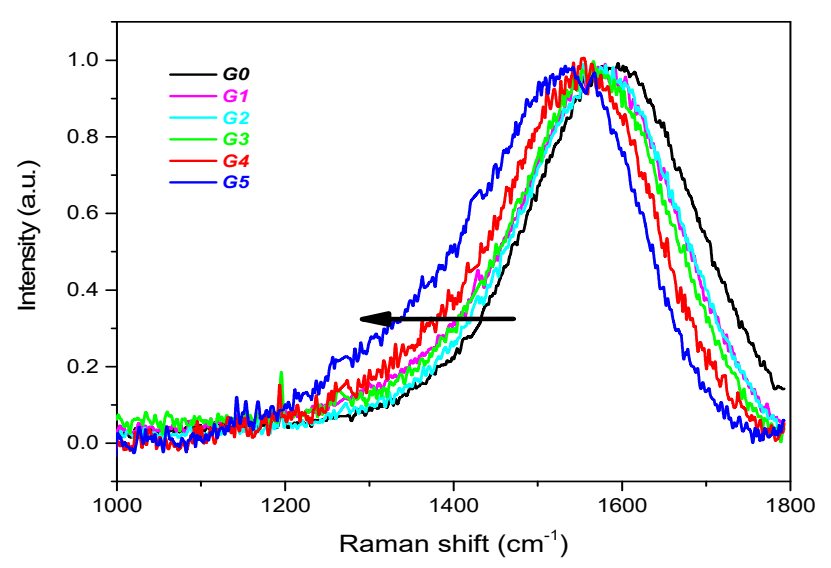

(a)

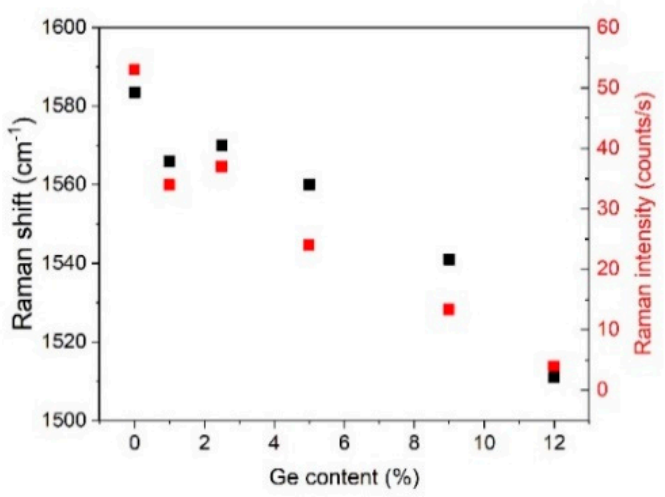

(b)

Figure 5. Raman spectra of the analysed samples. The arrow indicates increasing Ge content in DLC:Ge layers (a). Changes in the $\mathrm{G}$ band position and the Raman signal intensity (b) are illustrated.

The $\mathrm{C} \mathrm{sp} \mathrm{s}^{3}$ to $\mathrm{C} \mathrm{sp}^{2}$ structural evolution is frequently observed for metal-doped DLC layers $[9,27,34,50]$. Foong et al. [34] analysed Cu-doped DLC layers prepared by the laser deposition method. They pointed out that the presence of metal ions during laser deposition increased the heat dissipation on carbon matrix, which enhanced the formation of metallic nano-islands and graphitized the carbon matrix. Due to inversed bremsstrahlung process, the kinetic energy of the metal ions contained in plasma can be higher than in a single carbon system. This idea seems to be reasonable to explain the doping-induced structural evolution from the dominant $\mathrm{C} \mathrm{sp} \mathrm{sp}^{3}$ to $\mathrm{C} \mathrm{sp}^{2}$ bonds examined by ARXPS and RS spectroscopy.

Regarding the cytotoxicity of Ge-doped DLC layers, the present results clearly evidence that their cytotoxicity can be quite high even when the Ge doping is relatively low. The observed missing or low cytotoxicity in [20] can be masked by the capping carbon film formed on the top surface of the samples, when the Ge doping level is low and due to a mixture of Ge oxide and carbon species located at the surface, when the Ge content is higher.

\section{Conclusions}

We analysed hydrogen-free Ge-doped DLC layers using high-energy resolved corelevel photoelectron spectroscopy $\backslash$ low-energy ion scattering spectroscopy; and Raman spectroscopy. We proved the formation of the capping carbon film on the top of the low-doped sample that hindered the contact of Ge species with a tissue, thus explaining the absence of cytotoxicity. We next found that the top surfaces of the more doped DLC samples are enriched by carbon species. As a consequence, Ge species are enclosed by carbon atoms and provoked medium or high cytotoxicity, depending on the Ge content. Ge species located at the top surface of the samples were in an oxidized state and can be defined, in agreement with the published data, as the origin of cytotoxicity. Beneath the surface, Ge was dominantly bonded to carbon atoms. The results also confirmed the $\mathrm{C} \mathrm{sp}{ }^{3}$ to $\mathrm{C} \mathrm{sp}{ }^{2}$ structural evolution induced by the doping. The present results clearly implicate that the cytotoxicity of the DLC:Ge surfaces can be quite high even when the Ge doping is relatively low. The missing or low cytotoxicity can be masked by the capping carbon film formed on the top surface of the sample, when the Ge doping level is low and due to a mixture of Ge oxide and carbon species located at the surface when the Ge content is higher. Finally, we emphasize the importance of surface-sensitive methods for understanding the interaction between a solid surface and a tissue. 
Author Contributions: J.Z. Methodology, writing, editing. J.H. Photoelectron spectra evaluation, P.J. XPS and LEIS experiment, T.K. DLC and DLC:Ge layers deposition, M.L. Raman scattering experiment. M.J. conceptualization and supervision. All authors have read and agreed to the published version of the manuscript.

Funding: This research was funded by the CTU Grant Agency, the grant number SGS18/157/OHK4/2T/17. This work was also supported by the Strategy AV21 project, the Diagnostic Methods and Techniques programme, by Operational Programme Research, Development and Education financed by the EU Structural and Investment Funds and the MEYS CR Project No. CZ.02.1.01/0.0/0.0/16_026/0008382 (CARAT).

Data Availability Statement: Data available on request.

Conflicts of Interest: The authors declare no conflict of interest.

\section{References}

1. Lifshitz, Y. Diamond-like carbon-present status. Diam. Relat. Mater. 1999, 8, 1659-1676. [CrossRef]

2. Robertson, J. Diamond-like amorphous carbon. Mater. Sci. Eng. R Rep. 2002, 37, 129-281. [CrossRef]

3. Vetter, J. 60 years of DLC coatings: Historical highlights and technical review of cathodic arc processes to synthesize various DLC types, and their evolution for industrial applications. Surf. Coat. Technol. 2014, 257, 213-240. [CrossRef]

4. Bewilogua, K.; Hofmann, D. History of diamond-like carbon films-From first experiments to worldwide applications. Surf. Coat. Technol. 2014, 242, 214-225. [CrossRef]

5. Love, C.A.; Cook, R.B.; Harvey, T.J.; Dearnley, P.A.; Wood, R.J.K. Diamond like carbon coatings for potential application in bio-logical implants-A review. Tribol. Int. 2013, 63, 141-150. [CrossRef]

6. Hauert, R.; Thorwarth, K. An overview on diamond-like carbon coatings in medical applications. Surf. Coat. Technol. 2013, 233, 119-130. [CrossRef]

7. Barkhudarov, E.M.; Kossyi, I.A.; Anpilov, A.M.; Ivashkin, P.I.; Artem‘ev, K.V.; Moryakov, I.V.; Misakin, M.A.; Christofi, N.; Burmistrov, D.E.; Smirnova, V.V.; et al. New nanostructured carbon coating inhib-its bacterial growth, but does not influence on animal cells. Nanomaterials 2020, 10, 2130. [CrossRef] [PubMed]

8. Al-Jumaili, A.; Alancherry, S.; Bazaka, K.; Jacob, M.V. Review on the Antimicrobial Properties of Carbon Nanostructures. Materials 2017, 10, 1066. [CrossRef]

9. Zemek, J.; Houdkova, J.; Jiricek, P.; Jelinek, M.; Jurek, K.; Kocourek, T.; Ledinsky, M. In-depth distribution of ele-ments and bonding in the surface region of calcium-doped diamond-like carbon films. Appl. Surf. Sci. 2021, 539, 148250. [CrossRef]

10. Dobrzinski, D.; Boguszewska-Czubara, A.; Sugimori, K. Hydrochemical and biomedical insights into germanium potential of curative waters: A case study of health resorts in the Sudetes Mountains (Poland). Environ. Geochem. Health 2018, 40, 1355-1375. [CrossRef] [PubMed]

11. Mertens, R.T.; Parkin, S.; Awuach, S.G. Exploring six-coordinate germanium(IV)- diketonate complexes as anti-cancer agents. Inorg. Chem. Acta 2020, 503, 119375. [CrossRef]

12. Gao, Y.; Wang, S.Q.; Yang, C.Y.; An, N.; Liu, Z.; Yan, M.; Guo, C.S. A near-infrared responsive germanium com-plex of Ge/GeO 2 for targeted tumor phototherapy. J. Mat. Chem. B 2019, 7, 5056-5064. [CrossRef]

13. Cho, J.M.; Chae, J.; Jeong, S.R.; Moon, M.J.; Shin, D.Y.; Lee, J.H. Immune activation of Bio-Germanium in a randomized, doubleblind, placebo-controlled clinical trial with 130 human subjects: Therapeutic opportunities from new insights. PLoS ONE 2020, 15, e0240358. [CrossRef] [PubMed]

14. Wada, T.; Hanyu, T.; Nozaki, K.; Kataoka, K.; Kawatani, T.; Asahi, T.; Sawamura, N. Antioxidant Activity of Ge-132, a Synthetic Organic Germanium, on Cultured Mammalian Cells. Biol. Pharm. Bull. 2018, 41, 749-753. [CrossRef]

15. Hwa, S.-H.; Bolger, P.M. Hazard assessment of germanium supplements. Regul. Toxicol. Pharmacol. 1997, $25,211-219$.

16. Cheong, Y.H.; Kim, S.U.; Seo, D.C.; Chang, N.I.; Lee, J.B.; Park, J.H.; Heo, J.-S.; Cho, J.-S. Effect of Inorganic and Organic Germanium Treatments on the Growth of Lettuce (Lactuca sativa). J. Korean Soc. Appl. Biol. Chem. 2009, 52, 389-396. [CrossRef]

17. Bhattacharjee, S.; Rietjens, I.M.C.M.; Singh, M.P.; Atkins, T.M.; Purkait, T.K.; Xu, Z.; Regli, S.; Shukaliak, A.; Clark, R.J.; Mitchell, B.S.; et al. Cy-totoxicity of surface-functionalized silicon and germanium nanoparticles: The dominant role of surface charges. Nanoscale 2013, 5, 4870-4883. [CrossRef]

18. Zhi, B.; Yang, Y.; Hudson-Smith, N.V.; Kortshagen, U.R.; Haynes, C.L. Bacterial toxicity of germanium nanocrys-tals induced by doping with boron and phosphorus. ACS Appl. Nano Mater. 2019, 2, 4744-4755. [CrossRef]

19. Robertson, S.N.; Gibson, D.; Mackay, W.G.; Reid, S.; Williams, C.; Birney, R. Investigation of the antimicrobial properties of modified multilayer diamond-like carbon coatings on 316 stainless steel. Surf. Coat. Technol. 2017, 314, 72-78. [CrossRef]

20. Jelinek, M.; Kocourek, T.; Jurek, K.; Jelinek, M.; Smolková, B.; Uzhytchak, M.; Lunov, O. Preliminary Study of Ge-DLC Nanocomposite Biomaterials Prepared by Laser Codeposition. Nanomaterials 2019, 9, 451. [CrossRef] [PubMed]

21. Kovtun, A.; Jones, D.; Dell'Elce, S.; Treossi, E.; Liscio, A.; Palermo, V. Accurate chemical analysis of oxygenated graphene-based materials using X-ray photoelectron spectroscopy. Carbon 2019, 143, 268-275. [CrossRef] 
22. Gupta, N.; Veettill, B.P.; Conibeer, G.; Shrestha, S. Effect of substrate temperature and radio frequency power on compositional, structural and optical properties of amorphous germanium carbide films deposited using sputtering. J. Non-Cryst. Solids 2016, 443, 97-102. [CrossRef]

23. Han, J.; Jiang, C.; Zhu, J. Non-hydrogenated amorphous germanium carbide with adjustable microstructure and properties: A potential anti-reflection and protective coating for infrared windows. Surf. Interface Anal. 2012, 45, 685-690. [CrossRef]

24. Che, X.-S.; Liu, Z.-T.; Li, Y.-P.; Tan, T.-T. Effects of radio frequency power on the optical and electrical properties of germanium carbon films. J. Alloy. Compd. 2013, 577, 15-18. [CrossRef]

25. Zhan, C.-Y.; Wang, L.-W.; Huang, N.-K. Effect of bias on content of GeC in Ge1-xCx films. Chin. Phys. Lett. 2007, $24,803$.

26. Jiang, C.; Zhu, J.; Han, J.; Cao, W. The surface topography, structural and mechanical properties of Ge1-xCx films prepared by magnetron co-sputtering. J. Non-Cryst. Solids 2014, 383, 126-130. [CrossRef]

27. Zemek, J.; Houdkova, J.; Jiricek, P.; Jelinek, M. Amorphous carbon nanocomposite films doped by titanium: Sur-face and sub-surface composition and bonding. Diam. Relat. Mater. 2018, 81, 61-69. [CrossRef]

28. Merel, P.; Tabbal, M.; Chaker, M.; Moisa, S.; Margot, J. Direct evaluation of the $\mathrm{sp}^{3}$ content in dia-mond-like-carbon films by XPS Appl. Surf. Sci. 1998, 136, 105-110. [CrossRef]

29. Haerle, R.; Riedo, E.; Pasquarello, A.; Baldereschi, A. sp2/sp3hybridization ratio in amorphous carbon from C1score-level shifts: X-ray photoelectron spectroscopy and first-principles calculation. Phys. Rev. B 2001, 65, 045101. [CrossRef]

30. Leiro, J.; Heinonen, M.; Laiho, T.; Batirev, I. Core-level XPS spectra of fullerene, highly oriented pyrolitic graphite, and glassy carbon. J. Electron Spectrosc. Relat. Phenom. 2003, 128, 205-213. [CrossRef]

31. Zemek, J.; Houdkova, J.; Jiricek, P.; Jelinek, M. Surface and in-depth distribution of $\mathrm{sp}^{2}$ and $\mathrm{sp}^{3}$ coordinated car-bon atoms in diamond-like carbon films modified by argon ion bombardment during growth. Carbon 2018, 134, 71-79. [CrossRef]

32. Prabhakaran, K.; Ogino, T. Oxidation of Ge(100) and Ge(111) surfaces: An UPS and XPS study. Surf. Sci. 1995, 325, $263-271$. [CrossRef]

33. Wolter, S.; Tyler, T.; Jokerst, N. Surface characterization of oxide growth on porous germanium films oxidized in air. Thin Solid Films 2012, 522, 217-222. [CrossRef]

34. Foong, Y.M.; Koh, A.T.T.; Ng, H.Y.; Chua, D.H.C. Mechanism behind the surface evolution and microstructure changes of laser fabricated nanostructured carbon composite. J. Appl. Phys. 2011, 110, 54904. [CrossRef]

35. Shinotsuka, H.; Powell, C.J.; Penn, D.R. Calculations of electron inelastic mean free paths. X. Data for 41 ele-mental solids over the $50 \mathrm{eV}$ to $200 \mathrm{keV}$ range with the relativistic full Pen algorithm. Surf. Interface Anal. 2015, 47, 871-888. [CrossRef]

36. Jablonski, A.; Powell, C.J. Practical expressions for the mean escape depth, the information depth, and the effec-tive attenuation length in Auger-electron spectroscopy and x-ray photoelectron spectroscopy. J. Vac. Sci. Technol. A 2009, 27, 253-261. [CrossRef]

37. Takabayashi, S.; Motomitsu, K.; Takahagi, T.; Terayama, A.; Okamoto, K.; Nakatani, T. Qualitative analysis of a diamondlike carbon film by angle-resolved x-ray photoelectron spectroscopy. J. Appl. Phys. 2007, 101, 103542. [CrossRef]

38. Lesiak, B.; Kövér, L.; Tóth, J.; Zemek, J.; Jiricek, P.; Kromka, A.; Rangam, N. Csp2/sp3 hybridisations in carbon nanomaterialsXPS and (X)AES study. Appl. Surf. Sci. 2018, 452, 223-231. [CrossRef]

39. Brongersma, H.H.; Draxler, M.; de Ridder, M.; Bauer, P. Surface composition analysis by low-energy ion scatter-ing. Surf. Sci. Reps. 2007, 62, 63-101. [CrossRef]

40. Mikhailov, S.N.; van den Oetelaar, L.C.A.; Brongersma, H.H. Strong matrix effect in low- energy He+ ion scatter-ing from carbon. Nucl. Instr. Meth. Phys. Res. B 1994, 93, 210-214. [CrossRef]

41. Průša, S.; Procházka, P.; Bábor, P.; Šikola, T.; Ter Veen, R.; Fartmann, M.; Grehl, T.; Brüner, P.; Roth, D.; Bauer, P.; et al. Highly Sensitive Detection of Surface and Intercalated Impurities in Graphene by LEIS. Langmuir 2015, 31, 9628-9635. [CrossRef]

42. Bom, N.; Soares, G.; Krug, C.; Baumvol, I.; Radtke, C. Probing the stability of Al2O3/Ge structures with ion beams. Nucl. Instrum. Methods Phys. Res. Sect. B 2012, 273, 146-148. [CrossRef]

43. Hueper, W.C. Effects of overdoses of germanium dioxid upon the blood and tissues of rabbits. Am. J. Med. Sci. 1931, 181, 820-829. [CrossRef]

44. Chiu, S.-J.; Lee, M.-Y.; Chen, H.-W.; Chou, W.-G.; Lin, L.-Y. Germanium oxide inhibits the transition from G2 to M phase of CHO cells. Chem. Interact. 2002, 141, 211-228. [CrossRef]

45. Davis, C.A.; Amaratunga, G.A.J.; Knowles, K.M. Growth Mechanism and Cross-Sectional Structure of Tetrahedral Amorphous Carbon Thin Films. Phys. Rev. Lett. 1998, 80, 3280-3283. [CrossRef]

46. Soin, N.; Roy, S.S.; Ray, S.C.; Lemoine, P.; Rahman, A.; Maguire, P.D.; Mitra, S.K.; McLaughlin, J.A. Thickness dependent electronic structure of ultra-thin tetrahedral amorphous carbon (ta-C) films. Thin Solid Films 2012, 520, 2909-2915. [CrossRef]

47. Kohary, K.; Kugler, S. Growth of amorphous carbon: Low-energy molecular dynamics simulation of atomic bombardment. Phys. Rev. B 2001, 63, 193404. [CrossRef]

48. Marks, N. Thin film deposition of tetrahedral amorphous carbon: A molecular dynamics study. Diam. Relat. Mater. 2005, 14, 1223-1231. [CrossRef]

49. Ferrary, A.C.; Robertson, J. Interpretation of Raman spectra of disordered and amorphous carbon. Phys. Rev. B 2000, 61, 14095-14107. [CrossRef]

50. Dey, R.; Dolai, S.; Hussain, S.; Bhar, R.; Pal, A.K. Phosphorus doping of diamond-like carbon films by radio fre-quency CVD-cumevaporation technique. Diam. Relat. Mater. 2018, 82, 70-78. [CrossRef] 